\title{
Damping performance of bamboo fibre-reinforced green composites
}

\author{
H. Takagi ${ }^{1}$, H. Mori ${ }^{1} \&$ M. Nakaoka ${ }^{2}$ \\ ${ }^{1}$ Institute of Technology and Science, \\ The University of Tokushima, Japan \\ ${ }^{2}$ Tokushima Prefectural Industrial Technology Center, Japan
}

\begin{abstract}
Functionality of natural fibre-reinforced composites continually attracts attention and offers a unique possibility. We fabricated several types of unidirectional and random bamboo fibre green composites, and examined their damping properties as a function of bamboo fibre content, fibre length, and fibre morphology. The loss factors of the bamboo fibre green composites decreased with increasing bamboo fibre content. However, the loss factors gradually decreased in the composites reinforced with fibre content higher than 40 mass $\%$. The loss factors of random short fibre $(10 \mathrm{~mm})$ reinforced green composites were higher than those of unidirectional ones. It can be seen that the damping factor of bamboo fibre green composites depended on fibre length and fibre content, and that vibration damping properties of the bamboo green composites were better than those of glass fibre reinforced plastics.
\end{abstract}

Keywords: green composites, bamboo fibre, starch, damping, loss factor.

\section{Introduction}

At present, glass-fibre reinforced plastics (GFRP) are widely used in machine structures such as automobile and aircraft [1]. The GFRP have many advantages in terms of high mechanical performance and chemical stability, however they also have serious disadvantages after use; namely the technical difficulty in recycling; environmental load is high. Therefore, the development of the structural composite materials of which the environmental loading is smaller than conventional ones is required [2-5]. The green composites (fully biodegradable composite materials) which are composed of biodegradable resin and high strength 
natural fibre have been developed in recent years [6-10]. Much research has been focused on their mechanical properties; tensile strength and elastic modulus. However, little is known about their functionality such as biodegradability [11], heat-insulation [12-14], sound absorbency and damping characteristics [15]. In this study, green composites which are reinforced by various type of bamboo fibre were produced, and their damping characteristics were investigated.

\section{Experimental methods}

\subsection{Materials}

Moso bamboo fibre (hereafter called "bamboo fibre") was obtained by a steamexplosion method [16], and was used as reinforcement in green composites. A starch-based dispersion type biodegradable resin (CP-300, Miyoshi Oil \& Fat Co., Ltd., Japan) was used as the matrix polymer.

\subsection{Details of specimens}

Five types of bamboo fibre-reinforced green composites were fabricated; they were reinforced by unidirectional long bamboo fibre, unidirectional short bamboo fibre, random short bamboo fibre, random cotton-like bamboo fibre, and bamboo powder. Fibre weight content of the composites was varied from 6 mass $\%$ to $64 \mathrm{mass} \%$.

\subsection{Unidirectional long bamboo fibre composites}

The Unidirectional long bamboo fibre composites were produced by hot-pressing method by using a set of metallic press mould and hand-operated hydraulic press (NT-20H, Aisem Co. Ltd., Japan). Firstly the water-dispersion type biodegradable resin (CP-300) was mixed with the bamboo fibre, and then the mixture was dried at $105^{\circ} \mathrm{C}$ for $2 \mathrm{~h}$ in an oven (DRX420DA, Advantec Toyo Kaisha, Ltd., Japan), resulting in unidirectional composite preform sheets. The preform sheets were set in the metallic mould, then heated up to $140^{\circ} \mathrm{C}$, after reaching the temperature applied pressure to $10 \mathrm{MPa}$ for $10 \mathrm{~min}$, followed by air-cooling for $25 \mathrm{~min}$.

\subsection{Unidirectional short bamboo fibre composites}

The bamboo fibre was cut into a predetermined length $(5$ or $10 \mathrm{~mm})$ with scissors. The short bamboo fibre and biodegradable resin (CP-300) were unidirectionally arranged on a $\mathrm{V}$-shaped plastic plate in order to establish unidirectional alignment of short bamboo fibre. Then the mixture was dried at $105^{\circ} \mathrm{C}$ for $2 \mathrm{~h}$, resulting in preform sheets of unidirectional short bamboo fibre composites. The preform sheets were also hot-pressed as described above. 


\subsection{Random short bamboo fibre composites}

The dispersion-type biodegradable resin (CP-300) was filled with a shallow plate, and then the short bamboo fibre (5 or $10 \mathrm{~mm}$ long) was scattered on the biodegradable resin randomly. The mixture was dried in an oven at $105^{\circ} \mathrm{C}$ for $2 \mathrm{~h}$, resulting in preform sheets of random short bamboo fibre composites. The preform sheets were also hot-pressed as described above.

\subsection{Random cotton-like bamboo fibre composites}

The short bamboo fibre was mixed with warm water at $80^{\circ} \mathrm{C}$ by using a home-use high-speed mixer for $10 \mathrm{~min}$. During this mixing, the short bamboo fibre was split into cotton-like technical bamboo fibre (namely elementary fibre or single fibre) of about $15 \mu \mathrm{m}$ in diameter. The cotton-like bamboo fibre was mixed with the same biodegradable resin (CP-300), then dried in an oven, and finally hot-pressed as described above.

\subsection{Bamboo powder composites}

Bamboo sawdust (bamboo powder) was used as a raw material for the bamboo powder composites. The bamboo powder was mixed with the biodegradable resin (CP-300) in the small container with a capacity of 0.5 litres. This mixture was dried in an oven at $105^{\circ} \mathrm{C}$ for $2 \mathrm{~h}$, and finally hot-pressed as described above.

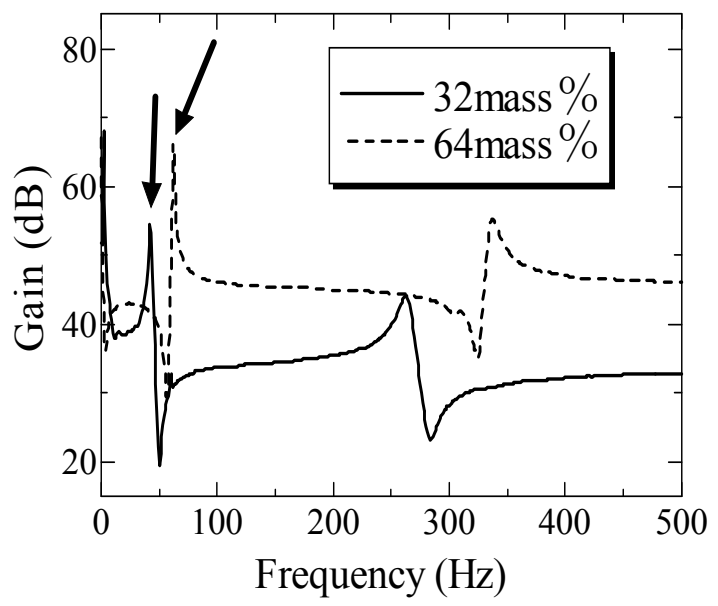

Figure 1: Example of transfer function of bamboo fibre composites with different fibre content.

\subsection{Damping testing}

Using the damping characteristic evaluation equipment (Type 2816, Bruel \& Kjaer, Denmark), the test samples produced in the section 2.3-2.7 were shaken in the centre, and loss factor was obtained by a half value method. Shape of the damping 
test specimen was $10 \mathrm{~mm}$ wide, $200 \mathrm{~mm}$ long and $1 \mathrm{~mm}$ thick. A typical transfer function of unidirectional composites ( 32 and 64 mass\% bamboo fibre content) is shown in Fig. 1. The loss factor of the composites is evaluated at the first vibration mode as indicated by arrows. The resonant frequency increases with increasing bamboo fibre content.

\subsection{Tensile testing}

Tensile tests of all the samples were carried out on an Instron universal testing machine (Model 5567, USA) with tensile speed of $1.0 \mathrm{~mm} / \mathrm{min}$. Shape of the tensile test specimen was $10 \mathrm{~mm}$ wide, $200 \mathrm{~mm}$ long and $1 \mathrm{~mm}$ thick, and the gauge length was $70 \mathrm{~mm}$.

\section{Results and discussion}

\subsection{Effect of fibre length on damping characteristics}

The relationship between loss factor of the unidirectional bamboo fibre composites (51-53 mass\% bamboo fibre content) and bamboo fibre length is shown in Fig. 2. It can be seen that the loss factor decreases with increasing fibre length. In general, the composites reinforced by shorter fibre have lower elastic modulus, and thus larger kinetic energy can be changed into heat, and resulting in higher loss factor [17].

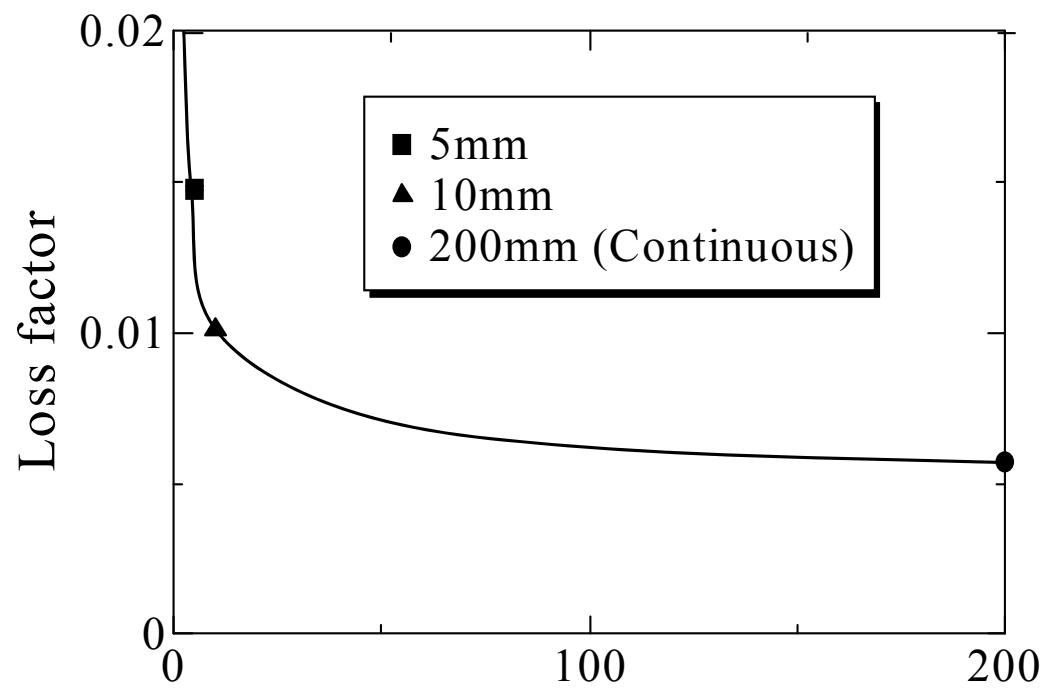

Fibre length $(\mathrm{mm})$

Figure 2: Relationship between loss factor of unidirectional bamboo fibre green composites and fibre length. 


\subsection{Effect of fibre morphology on damping characteristics}

The loss factors of random short fibre composites (55 mass $\%$ bamboo fibre content) are indicated in Fig. 3. The morphology of the composite sample evaluated is $10 \mathrm{~mm}$ short fibre, $5 \mathrm{~mm}$ short fibre, cotton-form fibre, and bamboo powder. The loss factor of the random fibre composites varies greatly sample to sample. The composites reinforced by shorter or smaller bamboo fibre have higher loss factor, therefore the bamboo powder composites have the highest loss factor. One possible reason for this might be that the composites reinforced by shorter or smaller bamboo fibre also have lower elastic modulus [1], and thus the energy consumption of the composites during deformation becomes larger.

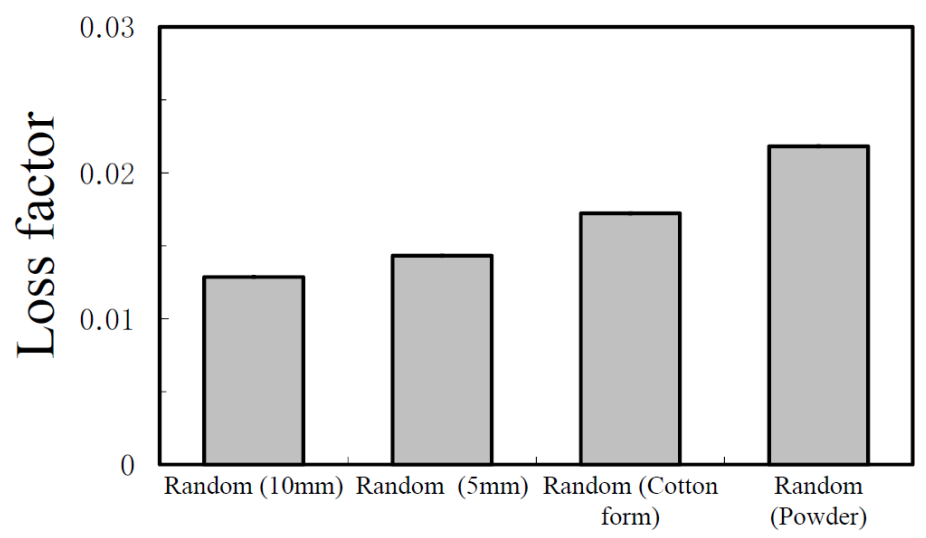

Figure 3: Variation in loss factor of bamboo fibre green composites with different fibre morphology.

\subsection{Effect of fibre content on damping characteristics}

The relationship between loss factor for unidirectional long fibre composites and short $(10 \mathrm{~mm})$ random fibre random composites and fibre content is depicted in Fig. 4. The loss factors for both composites decreases rapidly and then saturates as the fibre content increases. It should be noted that short random fibre composites have higher loss factor in a similar manner to the case in Fig. 3 and that vibration damping properties of the bamboo green composites were better than that of glass fibre reinforced plastics [17].

\section{Conclusions}

Based on the experimental results obtained, the following conclusions can be made:

(1) The loss factor of bamboo fibre-reinforced composites increased as the fibre length is shorter.

(2) Long unidirectional composites have the smallest loss factor among the composites tested in this study. 
(3) The loss factor of random bamboo fibre composites is higher than that of unidirectional ones when compared at the same fibre content.

(4) The loss factor decreases with increasing fibre content without depending on fibre morphology, namely unidirectional or random reinforcement.

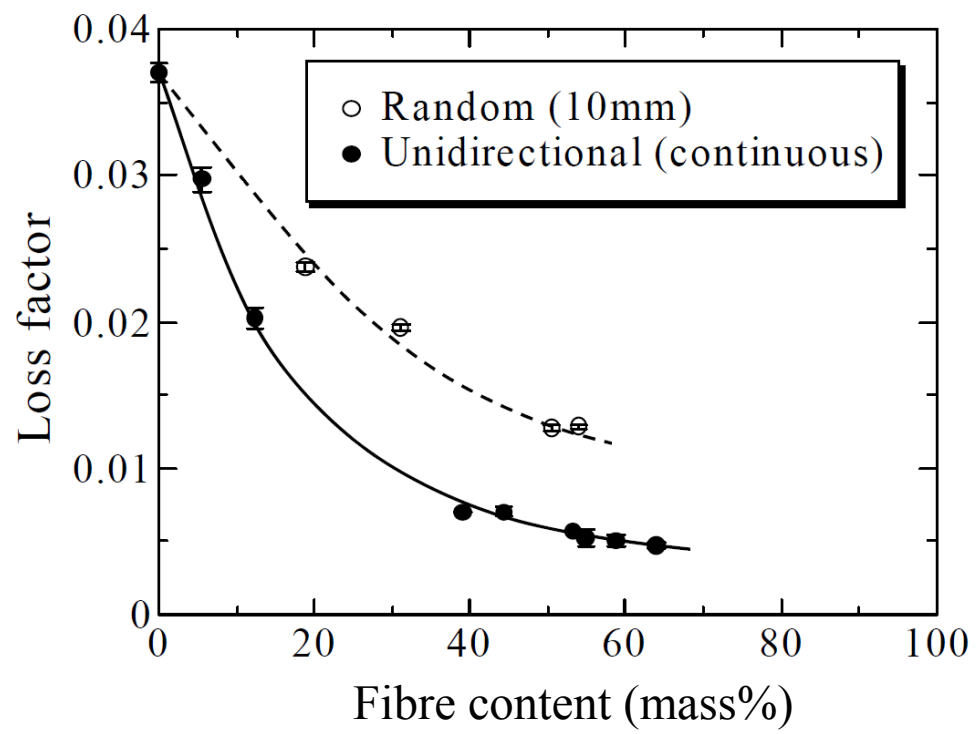

Figure 4: Relationship between loss factor of bamboo fibre green composites and fibre content.

\section{References}

[1] Hosam El-Din M. Saleh, Polyester, InTec: Rijeka, pp. 135-166, 2012.

[2] Netravali, A. N. \& Chabba, S., Composites get greener. Materials Today, 6(4), pp. 22-29, 2003.

[3] Omrani, A., Simon, L. C. \& Rostami, A. A., Influences of cellulose nanofibre on the epoxy network formation. Materials Science and Engineering A, 490(1-2), pp. 131-137, 2008.

[4] Wambua, P. Ivens, J. \& Verpoest, I., Natural fibres: can they replace glass in fibre reinforced plastics?. Composites Science and Technology, 63(9), pp. 1259-1264, 2003.

[5] Pandey, J. K., Nakagaito, A. N. \& Takagi, H., Fabrication and applications of cellulose nanoparticle-based polymer composites. Polymer Engineering and Science, 53(1), pp. 1-8, 2013.

[6] Luo, S. \& Netravali, A. N., Interfacial and mechanical properties of environment-friendly "green" composites made from pineapple fibres and poly(hydroxybutyrate-co-valerate) resin. Journal of Materials Science, 34(15), pp. 3709-3719, 1999. 
[7] Luo, S. \& Netravali, A. N., Mechanical and thermal properties of environment-friendly green composites made from pineapple leaf fibres and poly (hydroxybutyrate-co-valerate) resin. Polymer Composites, 20(3), pp. 367-378, 1999.

[8] Lodha, P. \& Netravali, A. N., Characterization of interfacial and mechanical properties of "green" composites with soy protein isolate and ramie fibre. Journal of Materials Science, 37(17), pp. 3657-3665, 2002.

[9] Mueller, D. H. \& Krobjilowski, A., New discovery in the properties of composites reinforced with natural fibres. Journal of Industrial Textiles, 33(2), pp. 111-130, 2003.

[10] Pandey, J. K., Takagi, H., Nakagaito, A. N., Saini, D. R. \& Ahn, S. H., An overview on the cellulose based conducting composites. Composites Part B-Engineering, 43(7), pp. 2822-2826, 2012.

[11] Shibata, M., Oyamada, S., Kobayashi, S. \& Yaginuma, D., Mechanical properties and biodegradability of green composites based on biodegradable polyesters and lyocell fabric. Journal of Applied Polymer Science, 92(6), pp. 3857-3863, 2004.

[12] Takagi, H. Kako, S. Kusano, K. \& Ousaka, A., Thermal conductivity of PLA-bamboo fibre composites. Advanced Composite Materials, 16(4), pp. 377-384, 2007.

[13] Liu, K. Takagi, H. Osugi, R. \& Yang Z., Evaluation of transverse thermal conductivity of Manila hemp fibre in solid region using theoretical method and finite element method. Materials and Design, 32(8-9), pp. 4586-4589, 2011.

[14] Takagi, H., Liu, K. Osugi, R., Nakagaito, A.N. \& Yang Z., Heat barrier properties of green composites. Journal of Biobased Materials and Bioenergy, 6(4), pp. 470-474, 2012.

[15] Kamal, A. M. \& Taha, I. M., Vibration damping behavior of fiber reinforced composites: A Review. Key Engineering Materials, 425, pp. 179-194, 2010.

[16] Takagi, H. \& Ichihara Y., Effect of fibre length on mechanical properties of "green" composites using a starch-based resin and short bamboo fibres. JSME International Journal, Series A, 47(4), pp. 551-555, 2004.

[17] Subramanian, C., Deshpande, S. B. \& Senthilvelanc, S., Effect of reinforced fiber length on the damping performance of thermoplastic composites. Advanced Composite Materials, 20(4), pp. 319-335, 2011. 